\title{
The hypothalamus at the crossroads of psychopathology and neurosurgery
}

\author{
Daniel A. N. Barbosa, ${ }^{1,2}$ Ricardo de Oliveira-Souza, MD, PhD, ${ }^{1,3}$ Felipe Monte Santo, MD,,4 \\ Ana Carolina de Oliveira Faria, MSc, PhD, ${ }^{1,3}$ Alessandra A. Gorgulho, MD, MSc, ${ }^{5,6}$ and \\ Antonio A. F. De Salles, MD, PhD,5
}

\begin{abstract}
'Department of Clinical Neuroscience, D'Or Institute for Research and Education; '2Division of Neurosurgery and ${ }^{3}$ Department of Neurology and Psychiatry, Gaffrée e Guinle University Hospital, Federal University of the State of Rio de Janeiro; ${ }^{4}$ Intensive Care Unit, Icaraí Hospital, Niteroi, RJ; ${ }^{5} \mathrm{HC}$ r Neuroscience, São Paulo, Brazil; and ${ }^{6}$ Department of Neurosurgery and Radiation Oncology, David Geffen School of Medicine, University of California, Los Angeles, California
\end{abstract}

\begin{abstract}
The neurosurgical endeavor to treat psychiatric patients may have been part of human history since its beginning. The modern era of psychosurgery can be traced to the heroic attempts of Gottlieb Burckhardt and Egas Moniz to alleviate mental symptoms through the ablation of restricted areas of the frontal lobes in patients with disabling psychiatric illnesses. Thanks to the adaptation of the stereotactic frame to human patients, the ablation of large volumes of brain tissue has been practically abandoned in favor of controlled interventions with discrete targets.

Consonant with the role of the hypothalamus in the mediation of the most fundamental approach-avoidance behaviors, some hypothalamic nuclei and regions, in particular, have been selected as targets for the treatment of aggressiveness (posterior hypothalamus), pathological obesity (lateral or ventromedial nuclei), sexual deviations (ventromedial nucleus), and drug dependence (ventromedial nucleus). Some recent improvements in outcomes may have been due to the use of stereotactically guided deep brain stimulation and the change of therapeutic focus from categorical diagnoses (such as schizophrenia) to dimensional symptoms (such as aggressiveness), which are nonspecific in terms of formal diagnosis. However, agreement has never been reached on 2 related issues: 1) the choice of target, based on individual diagnoses; and 2) reliable prediction of outcomes related to individual targets. Despite the lingering controversies on such critical aspects, the experience of the past decades should pave the way for advances in the field. The current failure of pharmacological treatments in a considerable proportion of patients with chronic disabling mental disorders is reminiscent of the state of affairs that prevailed in the years before the early psychosurgical attempts.

This article reviews the functional organization of the hypothalamus, the effects of ablation and stimulation of discrete hypothalamic regions, and the stereotactic targets that have most often been used in the treatment of psychopathological and behavioral symptoms; finally, the implications of current and past experience are presented from the perspective of how this fund of knowledge may usefully contribute to the future of hypothalamic psychosurgery.
\end{abstract}

https://thejns.org/doi/abs/10.3171/2017.6.FOCUS17256

KEY WORDS hypothalamus; deep brain stimulation; mental disorders; psychosurgery

$\mathrm{T}$ HE Cure of Folly (c. 1490), by the Dutch painter Hieronymus Bosch (1450-1516), depicts one of the earliest renderings of a neurosurgical procedure. ${ }^{82}$ The use of cranial surgery, however, possibly dates back to the earliest evidence of trepanation in humans. ${ }^{1}$ Viewed from this broad perspective, the modern era of psychosurgery is relatively recent. Its beginnings may be traced to the pioneering work of Gottlieb Burckhardt (1836-1907) and Egas Moniz (1874-1955), who disconnected large parts of the frontal lobes in patients with a variety of behavioral disorders..$^{43,54}$ In 1947, Ernest Spiegel (1895-1985) and Henry Wycis (1911-1972) introduced the first stereotactic device for use in mentally ill patients. ${ }^{96}$ This precise approach to brain sites allowed Spiegel and Wycis to ob-

ABBREVIATIONS CCH = chronic cluster headache; DBS = deep brain stimulation; DMN = dorsomedial nucleus; ICAP = Inventory for Client and Agency Planning; LHA = lateral hypothalamic area; MOAS = Modified OAS; OAS = Overt Aggression Scale; PM = posteromedial; PMH = posteromedial hypothalamus; PON = preoptic nuclei; PVZ = periventricular zone; QOLS = Quality of Life Scale; VM = ventromedial; VMH = ventromedial hypothalamus; VPH = ventroposterior hypothalamus.

SUBMITTED May 1, 2017. ACCEPTED June 20, 2017.

INCLUDE WHEN CITING DOI: 10.3171/2017.6.FOCUS17256. 
tain detailed electrophysiological recordings in the operating room, enabling the development of increasingly accurate and less radical procedures. Thereafter, more detailed knowledge of the neuroanatomical substrates of specific psychiatric symptoms could be applied to the planning of discrete neurosurgical targets. These operations have also provided novel insights into the neurological underpinnings of psychopathology.

In the last decades of the 20th century, 2 advances provided momentum to the practice of functional neurosurgery. Conceptually, indications for surgery subtly shifted from diagnoses to symptoms. For example, during the years after lobotomy was performed for "schizophrenia," indications for this procedure increasingly focused on symptoms, such as aggressiveness, which are not diagnosis specific. ${ }^{62,108}$ The other advance was technical, as shown by the substantial increase in the accuracy of stereotactic surgery due to major improvements in anatomical and functional imaging coupled with electrophysiological recording as confirmation of electrode placement. ${ }^{2}$ These techniques are progressively being incorporated into most current protocols of stereotactic psychosurgery.

With a volume of only $4 \mathrm{~cm}^{3}$, the human hypothalamus is an anatomically and functionally heterogeneous region seated at the base of the brain. It contains several nuclei that sustain intricate connections with each other as well as with distant parts of the brain and the endocrine system through the hypophysis. ${ }^{50,51}$ Creation of lesions and stimulation of discrete regions within the hypothalamus of experimental animals have proven their decisive contribution to the neural organization of fundamental approach (e.g., alimentary and sexual) and avoidance (e.g., fear) behaviors..$^{52,57,95,111,114}$ Targeting specific regions of the human hypothalamus has constituted a major technical challenge due to their location and myriad of passing fibers. Many such drawbacks may be circumvented by the development of novel techniques, such as neuromodulation, radiosurgery, and focused ultrasound. ${ }^{20,55,63}$

Along with the cingulate gyrus and bundle, the amygdala, the anterior limb of the internal capsule, and the subcaudate white matter, the hypothalamus has been a common target for the treatment of a heterogeneous collection of psychopathological symptoms..$^{64,73,85}$ Outcomes have ranged from poor to satisfactory to good. ${ }^{23,83,90}$ However, due to the controversial indications of psychosurgery, ethical objections, and the public backlash, the number of reports of hypothalamotomy for psychiatric conditions gradually decreased..$^{90,106}$ The main sources of controversy have included a contentious theoretical basis (mostly animal-based studies), poor description of preoperative clinical presentations, dubious diagnostic criteria, prior treatment schedules, surgical indications, and classification of outcomes. ${ }^{76,90}$

Since the establishment of deep brain stimulation (DBS) as a safe, reversible, and ethically acceptable procedure, together with the development of more refined stereotactic techniques and imaging visualization of anatomy, the hypothalamus has risen again as a surgical target for the treatment of specific psychopathological symptoms ${ }^{29}$ Hypothalamic DBS has been considered a possible therapeutic option for refractory obesity, panic disorder, and aggressive or disruptive behaviors in patients with mental impairment or brain damage ${ }^{31,113}$ For some of those conditions, encouraging results are becoming available in the literature.

This article has 3 objectives: 1) to describe the functional organization of the hypothalamus; 2) to review the stereotactic targets that have been used for the treatment of psychiatric illness and incidentally elicited behavioral changes when stimulated; and 3) to discuss the possible implications of these reports for the future of hypothalamic psychosurgery.

\section{Functional Organization of the Hypothalamus}

The human hypothalamus is a small anatomically heterogeneous brain region involved in a gamut of physiological processes ranging from vegetative and endocrine functions to higher-order social behavior. ${ }^{18,19,50,97}$ Strategically placed at the crossroads of multiple functional systems, the hypothalamus is composed of a complex array of nuclei and thin fibers that run chiefly in the medial forebrain bundle, in the fornix, and in the ansa peduncularis. ${ }^{39,50,51,69}$ In all vertebrate species, the hypothalamus is a paramedian division of the basal diencephalon that lies below the thalamus, where it makes up the floor and lateral walls of the third ventricle. ${ }^{49}$

The complex anatomy of the hypothalamus is best represented by a combination of coronal, axial, and parasagittal sections alternatively stained for nerve fibers and cell bodies. ${ }^{69}$ In a rostrocaudal direction (Fig. 1), 3 major regions-preoptic (or chiasmal), tuberal (or infundibular), and mammillary-are easily seen with the naked eye..$^{88}$ This rostrocaudal partition is supplemented by a tripartite mediolateral division represented by the periventricular, nuclear, and lateral zones, which form parallel zones with a distinctive cellular architecture and hodology. ${ }^{47}$ Table 1 summarizes the main hypothalamic nuclei that are known to be clinically relevant.

\section{The Periventricular Zone}

The periventricular zone (PVZ) is rudimentary in humans, in comparison with that of other mammals, consisting of a 1-mm-thick layer of subependymal neuron clusters without a clear structural organization; the PVZ is continuous with the periaqueductal gray substance with which it is connected through the dorsal longitudinal fascicle of Schütz. ${ }^{39}$ Despite the comparatively rudimentary structure of the human PVZ, its role in behavior is far from simple or unimportant. For example, Foerster and Gagel, in their 1933 publication, ${ }^{26}$ related that following removal of a cyst from the third ventricle of the patient in their Case 4, every time the surgeon gently wiped coagulated blood from the ventricle floor the patient burst out laughing, whistled, made jokes, and uttered obscene remarks. These fits of mania recurred as many times as the ventricle floor was swabbed, ceasing as contact was suspended. In 1957, Angelergues et al. ${ }^{5}$ reported a case of persistent euphoria in a patient who suffered a bilateral infarct of the PVZ without extension to the nuclear and lateral zones. Cases like those reported by Foerster and Gagel and Angelergues et al., although anecdotal, offer direct evidence for the critical role of a well-defined ana- 

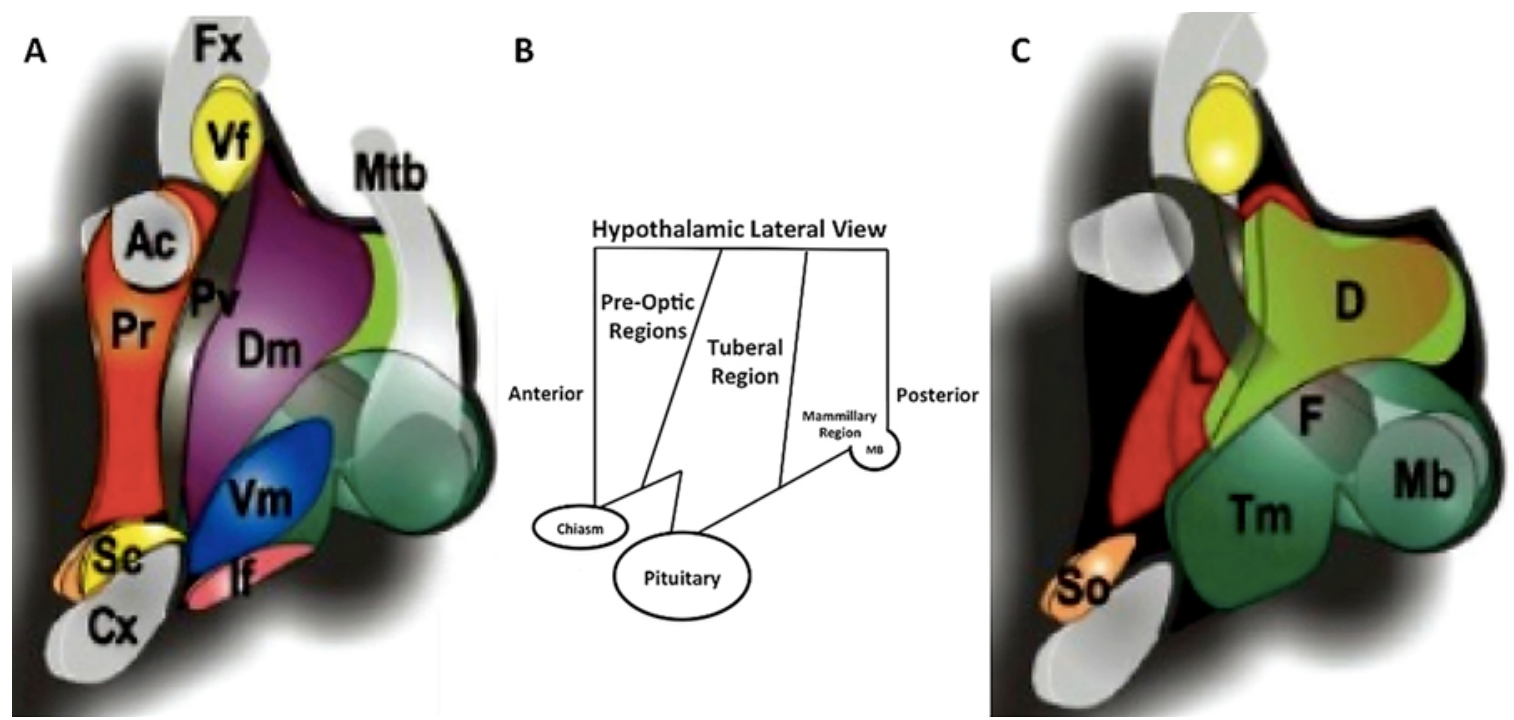

FIG. 1. A and C: Schematic drawings of hypothalamic nuclei, lateral view from the midline, showing the nuclei directly located under the wall of the third ventricle (A) and the more deeply located nuclei up to the lateral region (C). The fornix divides the hypothalamus into lateral and medial regions. B: Schematic showing the regions of the hypothalamus from anterior to posterior and the relationship of the hypothalamus to the optic chiasm, pituitary, and mammillary body. $\mathrm{Ac}=$ anterior commissure; $\mathrm{Cx}=\mathrm{optic} \mathrm{chiasm \text {; }}$ $D=$ dorsal or posterior nucleus; $D m=$ dorsomedial nucleus; $F=$ fornix nuclei; $F x=$ fornix; If = infundibular (arcuate) nucleus; $L=$ lateral nucleus; $\mathrm{Mb}=$ mammillary body; $\mathrm{Mtb}=$ mammillothalamic bundle; $\mathrm{Pr}=$ preoptic nuclei; $\mathrm{Pv}=$ paraventricular nucleus; $\mathrm{Sc}=$ suprachiasmatic (ovoid) nucleus; So = supraoptic (tangential) nucleus; Tm = tuberomammillary (mammilloinfundibularis) nucleus; $\mathrm{Vf}=$ ventricular foramen; $\mathrm{Vm}=$ ventromedial (tuber principal) nucleus. For targeting and stereotactic orientation in relation to the intercommissural (anterior commissure-posterior commissure) line, see Lemaire et al. ${ }^{50}$ Panels $A$ and $C$ are reproduced from Lemaire JJ, Nezzar H, Sakka L, Boirie Y, Fontaine D, Coste A, et al: Maps of the adult human hypothalamus. Surg Neurol Int 4:S156-163, 2013. CC BY-NC version 3.0 (https://creativecommons.org/licenses/by-nc/3.0/).

tomical division of the hypothalamus in mood regulation, a fact that may bear important therapeutic and surgical applications. ${ }^{5,26}$ The importance of the PVZ for overall body homeostasis is also shown by its unique relationship with the adenohypophysis. ${ }^{81}$ The collection of neurons located in the arcuate and paraventricular nuclei (the "hypophysiotrophic area") project to the portal system of the median eminence, where they secrete the hypothalamic hormones. ${ }^{35}$ At this point, the whole endocrine system is potentially open to all kinds of neural modulation issuing from multiple regions of the brain.

\section{The Nuclear Zone}

In contrast to the PVZ, the nuclear and lateral zones are larger (relative to overall brain volume) and more complex in humans compared with other mammals. ${ }^{15}$ The fornix divides these 2 zones as it pierces the hypothalamus on its way to the mammillary body. ${ }^{68}$

TABLE 1. Main hypothalamic nuclei in the rostrocaudal direction

\begin{tabular}{|c|c|}
\hline Hypothalamic Division \& Nucleus & Functional Associations \\
\hline \multicolumn{2}{|l|}{ Preoptic or chiasmal } \\
\hline Preoptic & Thermal regulation, endocrine regulation of sexual behavior \\
\hline Paraventricular & $\begin{array}{l}\text { Regulation of antidiuretic hormone \& oxytocin secretion, integration of neuroendocrine } \& \\
\text { autonomic response to stress }\end{array}$ \\
\hline Suprachiasmatic & Regulation of circadian rhythms \\
\hline Supraoptic & Secretion of neurohypophyseal hormones \\
\hline \multicolumn{2}{|l|}{ Tuberal or infundibular } \\
\hline Arcuate & Food intake, cardiovascular regulation, monitoring of adipose tissue fat \\
\hline Dorsomedial & Daytime feeding schedule, emotional responses to stress/panic-related behavior, libido \\
\hline Ventromedial & Food intake, weight gain/loss, lipolysis, sexual behavior \\
\hline \multicolumn{2}{|l|}{ Mammillary } \\
\hline Posterior & Sympathetic responses, defensive \& aggressive behaviors \\
\hline Tuberomammillary & Wakefulness; motivated behaviors in relation to food, water, sex, \& drugs \\
\hline Mammillary & Episodic memory encoding \\
\hline
\end{tabular}



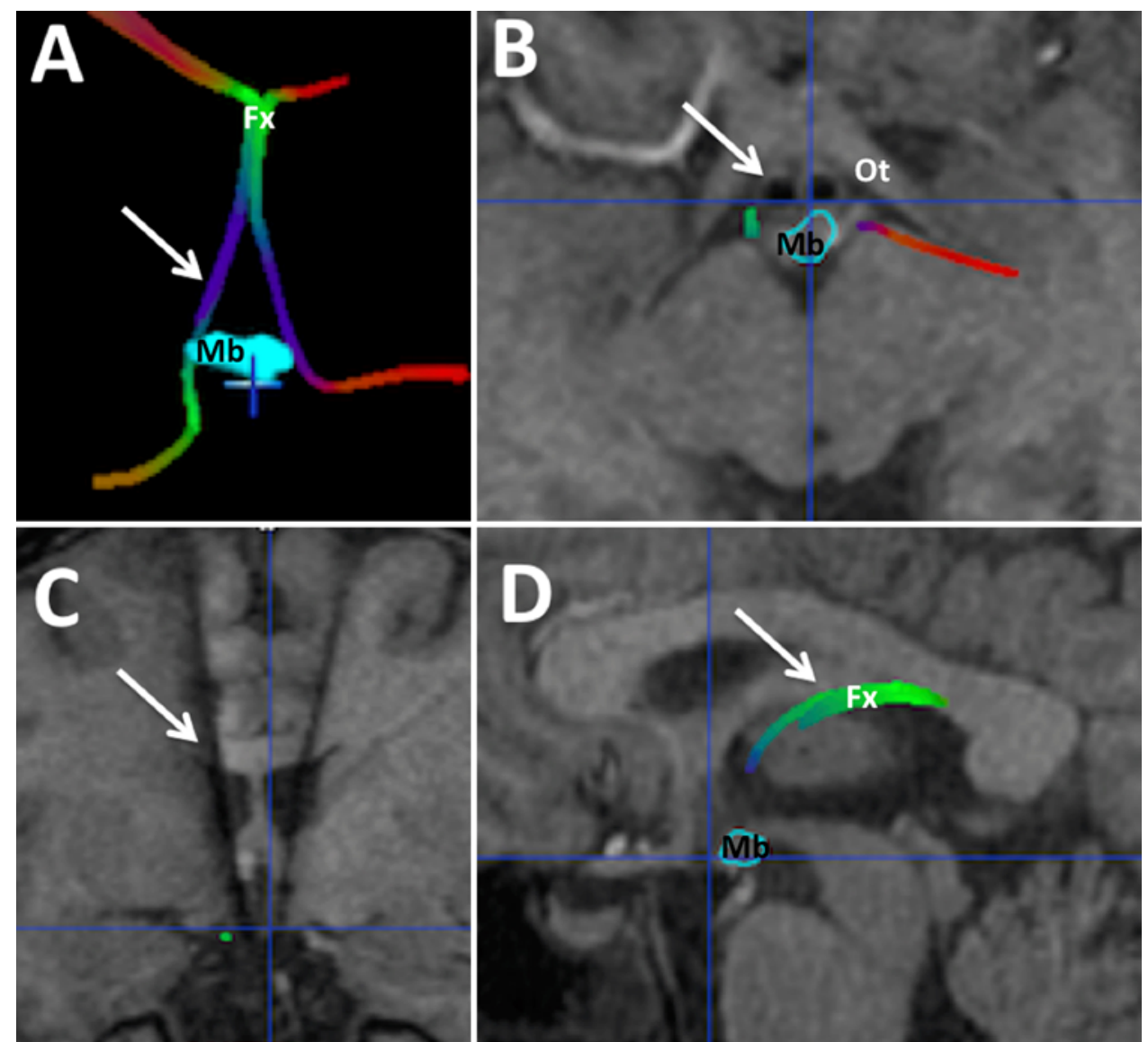

FIG. 2. MR images obtained in a patient with DBS electrodes implanted in the VMH. A: Tractographic (3D) rendering of the relationship of the mammillary bodies (Mb, light blue) with the fornix (Fx, arrow). B: Axial T1-weighted MR image showing the extension of the $\mathrm{VMH}$ electrode artifacts into the postchiasmatic region (arrow), just anterior to the Mb. The artifacts are medial to the optic tracts (Ot). C: Coronal T1-weighted MR image showing bilateral artifacts (arrow) due to the electrodes traversing the ventricles heading for the medial-most portion of the hypothalamus bilaterally. D: Sagittal T1-weighted MR image demonstrating the Fx as it dives into the hypothalamus (arrow), dividing it into medial and lateral regions, and ultimately reaching the Mb. Stimulation of electrodes in this location elicits a host of symptoms, such as sensation of heat, anxiety, tachycardia, blood pressure increase, recollections of autobiographic memories, and diaphoresis, which are related to the location of the contact stimulated from rostral to cranial, as well as to the parameters of stimulation.

The anterior hypothalamus is located medial to the optic chiasm..$^{51}$ Most rostral are the preoptic nuclei, which are involved in thermal regulation and in the endocrine regulation of sexual behavior. ${ }^{8,13,14}$ Caudal to the preoptic nuclei is the paraventricular nucleus, a vertical column of large cells in close relationship with the wall of the third ventricle (medially) and the column of the fornix (laterally). ${ }^{39}$ This nucleus takes part in the secretion of antidiuretic hormone and oxytocin by the posterior pituitary; it is also essential for the integration of the neuroendocrine and autonomic response to stress..$^{37,105}$ The suprachiasmatic nucleus also lies medially, immediately dorsal to the optic chiasm, and plays a role in the regulation of circadian rhythms. ${ }^{65,69}$ The supraoptic nucleus is slightly lateral, with a short extension rostral to the optic tract; like the paraventricular nucleus, it is also associated with the secretion of neurohypophyseal hormones. ${ }^{39}$

The tuberal (or infundibular) hypothalamus is rostrally continuous with the dorsal part of the anterior hypothalamus. The infundibular (or arcuate) nucleus is lo- cated anteroventrally, behind the optic chiasm, and forms the anterior wall of the infundibulum. ${ }^{51}$ It is involved in food intake, cardiovascular regulation, and the monitoring of adipose tissue fat. ${ }^{61,89,93,115}$ This region is also the location of the dorsomedial nucleus (DMN) and ventromedial nucleus (VMN), the latter being bounded dorsolaterally by the fornix. ${ }^{39}$ Lesions to the VMN modulate sexual behavior and lead to overeating and weight gain; ${ }^{23,101}$ DBS with electrodes located in this region increases lipolysis and leads to rejection of food and weight loss in animals and humans (Fig. 2). ${ }^{57,104}$ The DMN is bounded rostrally by the paraventricular nucleus and has been implicated in daytime feeding and the emotional responses to stress, such as panic-related behavior. ${ }^{25,34,39}$ Surgical lesions of this nucleus in both male and female patients have caused persistent impotence and loss of libido unrelated to the blood levels of sexual hormones ${ }^{58,59} \mathrm{High}$-frequency stimulation of this zone leads to sexual arousal. ${ }^{45}$

The posterior hypothalamus includes the posterior nucleus, the tuberomamillary nucleus, and the mammil- 
lary bodies ${ }^{46}$ Historically associated with sympathetic responses and defensive and aggressive behaviors, the posterior nucleus is limited caudally by the mammillothalamic tract. ${ }^{51,85,94}$ It is located above the tuberomammillary nucleus, which contains histaminergic neurons that have been implicated in the promotion of wakefulness and motivated behaviors in relation to food, water, sex, and drugs. ${ }^{17,51,67,71,102}$ The mammillary bodies constitute one of the major nodes of the classical circuit of Papez, which is essential for episodic memory encoding. ${ }^{109}$ The posterior hypothalamus and adjoining brainstem regions are critical for behavioral wakefulness, as originally proposed by von Economo based on clinicopathological cases of lethargic encephalitis. ${ }^{110}$

\section{The Lateral Zone}

The lateral hypothalamus represents the associative zone of the hypothalamus; a number of complex fiber systems make their way through this zone toward and from the hypothalamic nuclei in relation to distant regions of the forebrain and brainstem. ${ }^{68}$ The most conspicuous fiber systems that pass through the lateral hypothalamus comprise the medial forebrain bundle, the fornix, and the ansa peduncularis. ${ }^{42}$ The lateral hypothalamic area (LHA) also contains the lateral hypothalamic nucleus, which is ventrally and medially limited by the tuberomammillary nucleus. ${ }^{51}$ The lateral and ventromedial nuclei constitute the classical "feeding center" because they exert reciprocal functions in eating behavior. ${ }^{70}$ Thus, bilateral lesions of the LHA produce weight loss in experimental animals, while electrical stimulation of this region increases appetite and food intake. $3,21,98$

\section{The Hypothalamus as a Stereotactic Target Lessons From the Past: The Hypothalamotomies}

Four groups published the main papers on the hypothalamus as a psychosurgical target to treat refractory aggressive behavior. Sano, in a 1962 article, was the first to define this hypothalamic target as the site of maximum sympathetic response elicited by electrical stimulation, an area that is currently known as the "ergotropic, or Sano's triangle." 11,83 This procedure, initially called "sedative neurosurgery," was more efficient than other approaches, leading to calming effects in the first 22 cases. ${ }^{83,86}$ These results were confirmed in a series of 42 cases in which the patients were followed for 2 to 7 years, with outcomes categorized as "excellent" (12 patients became calm, with no violent, aggressive, or restless behavior, requiring no care or supervision) or "good" (28 patients became calm and tractable with only occasional irritability, requiring no constant care or supervision). ${ }^{85}$ In 1988, Sano and Mayanagi reported on the long-term outcome (10-25 years) for 37 of the 60 patients operated on from 1962 to 1977. The results were considered satisfactory in 29 cases (78\%); 18 of these 29 patients presented no violent or aggressive behavior postoperatively, allowing familial and social adaptation. ${ }^{84}$ A South American group presented a series of 11 cases in which patients were treated with bilateral or unilateral (1 case) posteromedial (PM) hypothalamotomy: 5 patients suffered from mental retardation, 2 patients were diagnosed with psychopathic personality, and 1 patient was diagnosed with schizophrenia. After 6-48 months of follow-up, 10 patients had satisfactory results, with social adaptation and complete disappearance of violent behavior in 7 cases ${ }^{92}$ From 1970 to 1972 , Arjona performed stereotactic lesions of the posteromedial hypothalamus (PMH) to treat aggressive behavior in 11 pediatric patients with mental retardation (age range 3-13 years) who did not respond to other treatments. After cryogenic lesions to the PMH (unilateral in 1 case), aggressive behavior and agitation improved in all patients, and they were later able to live at home and mix with other children. ${ }^{6}$

One group from India presented results of amygdalotomy and hypothalamotomy in the treatment of refractory aggressive behavior. ${ }^{774}$ One report published in 1975 included 49 patients who underwent PM hypothalamotomy, performed after failure of amygdalotomy in 33 cases. The results in the 8 cases in which primary bilateral PM hypothalamotomy was performed were considered "good." Unilateral primary hypothalamotomy had good results in 5 of 8 patients, while unilateral secondary procedures were considered useful in 15 of 20 patients. The authors suggested that unilateral hypothalamotomy may work well only in patients who have previously undergone amygdalotomy? Later, in an article published in 1988, Ramamurthi (from the same group) described his experience with 603 operations (122 hypothalamotomies) and concluded that about two-thirds of children with refractory aggressive behavior may benefit from amygdalotomy, hypothalamotomy, or a combination of both..$^{74}$

In the 1970s, based on evidence from animal studies and clinical observations, stereotactic lesions to the ventromedial hypothalamic nucleus (VMH) were also applied in the neurosurgical treatment of drug addiction. One case of intractable drug and alcohol addiction was included in Müller's series of hypothalamic psychosurgery. A 30-yearold man with a history of delirium, acute kidney failure, generalized epileptic seizures, and toxic liver damage due to heavy alcohol and drug intake underwent unilateral hypothalamotomy involving the right nucleus of Cajal and the lateral field of the tuber cinereum. ${ }^{62}$ Despite promising early effects on his addiction and lack of adverse effects (including changes in libido), he had to be committed to a psychiatric hospital 10 months after the surgery due to a relapse of alcoholism. ${ }^{64} \mathrm{In}$ a series of 13 patients treated with ventromedial (VM) hypothalamotomy (bilateral in 6 cases) for alcohol and drug addiction, 3-year follow-up showed increased self-control, but the patients also had increased appetite, weight gain, and reduced sexual drive. These unwanted effects made the treatment impractical, and it was abandoned. ${ }^{53}$

In 1974, a Danish group reported on a series of 5 patients with gross obesity who underwent exploratory electrical stimulation of the lateral hypothalamic area (LHA). ${ }^{73}$ A convincing hunger response was elicited in 3 cases. Right-sided hypothalamotomy of this region was performed in these patients. One of the patients also underwent an additional contralateral electrocoagulation procedure 3 months later. Even though the patients' body weight did not change significantly, the treated patients showed a considerable, although transient, decrease in spontaneous calorie intake, which was not observed in the other 2 patients who had only undergone exploratory 
surgery. The rationale for this operation was based on the harmful consequences of obesity together with the unsatisfactory results of other therapeutic options..$^{72}$

From the mid-1960s to the late 1970s, the indications for hypothalamotomy were extended to include the treatment of sexual deviations. ${ }^{23,64,77-80}$ The main stereotactic target was the right VMH (or Cajal's nucleus), which was destroyed bilaterally in some cases. ${ }^{23,80}$ Some of the conditions being treated were not well defined by the authors, and others (e.g., homosexuality) are no longer considered paraphilias. ${ }^{33,76}$ Hence, even though authors often speak of "improvement or cure of the sexual deviation," their cases and series must be analyzed with caution.

The first successful treatment of uncontrollable pedophilia by means of VM hypothalamotomy was performed in $1962 .{ }^{77}$ Although only limited outcome information is provided, aberrant sexual impulses were affirmed to be suppressed for the 3 years of follow-up. Interestingly, the patient also became incapable of indulging in erotic fantasies and stimulating visions. ${ }^{77}$ From that time until 1979, a total of 75 patients considered sexually abnormal were reported to have been subjected to hypothalamotomies in West Germany. ${ }^{90}$ In 1973, Müller et al. presented a case series of 22 patients, 20 of whom underwent VM hypothalamotomy for a variety of so-called "sexual deviations," mostly with good outcome. For undisclosed reasons, the ventromedial preoptic area was also lesioned in cases of heterosexual deviations in this series. One patient with pedophilic disorder who was considered successfully treated presented with hyperphagia and obesity at the 3-month follow-up visit; he had gained $32 \mathrm{~kg}$ from the operation. ${ }^{64}$ No matter how disputable the diagnostic categories of the time may be when judged by our current standards, VM hypothalamotomy reportedly reduced sexual drive in most cases as intended by the authors. ${ }^{33,90}$ Dieckmann et al. reported on 14 cases of aggressive sexual delinquency treated by unilateral VM hypothalamotomy from 1970 to 1979. Eight patients who were thoroughly examined were found to have great decreases in aggressive sexual traits and compulsions after surgery, allowing more harmonic family relationships and improved occupational situations. ${ }^{23} \mathrm{In}$ contrast to other reports, in this report, the authors claim that the structure of the patients' sexual organization remained unchanged (e.g., a pedophilic character is still retained), but it became possible for them to adapt their behavior to social norms. Increased appetite and weight gain were also observed in 5 patients and were considered a typical side effect of VM hypothalamotomy. ${ }^{23}$

After profound criticism and debate regarding psychosurgery in sex offenders in Germany, these operations were finally abandoned..$^{32,90}$ Decades later, Timmann and Müller interviewed 26 of the patients who had been operated on and reported good long-term follow-up and satisfaction of these individuals in a self-published book. ${ }^{33}$ These reports support the $\mathrm{VMH}$ as a region tightly related to sexual behavior, and this was confirmed by the observation of sexual behaviors in modern experimental primate work..$^{45}$

\section{Behavioral Effects of Hypothalamic Stimulation in the DBS Era}

The development of DBS and modern stereotactic tech- niques has allowed the resurgence of the hypothalamus as a target for ethically accepted psychosurgical interventions. The chief application of hypothalamic DBS for psychiatric patients has been refractory aggressive behavior in mentally impaired patients. Nevertheless, other potential uses of these procedures are increasingly being explored. A brief literature review on hypothalamic DBS for behavioral symptoms is summarized in Table 2 .

The DBS target for aggressive behavior follows the coordinates described decades ago by Keiji Sano. ${ }^{83}$ Four groups of authors have reported on results of bilateral PM hypothalamic DBS in a total of 19 patients. Franzini and collaborators presented a series of 7 patients with severe mental retardation who were operated on between 2002 and $2010 .{ }^{27}$ Six of these patients benefited from high-frequency stimulation of the PM hypothalamus with marked reduction in aggressive behavior as assessed by the Overt Aggression Scale (OAS), followed by simplification of family management and improvement in social interactions. ${ }^{12,27,29,30}$ Three years after the first favorable results of these studies, 2 other case reports of PMH DBS for aggressive behavior were published. ${ }^{38,44}$ A group from Madrid described the case of a male patient with idiopathic mental retardation and daily refractory aggressive crises who had good response to low-frequency stimulation as determined by evaluation with the Inventory for Client and Agency Planning (ICAP). At 18 months of follow-up, the patient had had 4 periods of aggressiveness, each lasting 2-3 days. ${ }^{38}$ Kuhn et al. reported on a case of a 22 -yearold woman with severe self-mutilating behavior after traumatic brain injury. Under high-frequency PMH DBS, she experienced a pleasant sense of inner peace and showed complete elimination of self-aggressive behavior during a 4-month observation period. ${ }^{44}$

In 2013, the same group from Madrid also presented long-term results of PMH DBS for intractable aggressiveness in a series of 6 patients with mental retardation..$^{103}$ Five showed a significant reduction in aggressiveness evaluated with the ICAP, while improvements in social interactions and sleep patterns were observed in 3 and 4 patients, respectively. Interestingly, the authors refer to similar responses with low- and high-frequency stimulation. ${ }^{103}$ In another series, 4 patients with moderate to severe cognitive compromise underwent PMH DBS for aggressive behavior associated with Sotos syndrome and nongenetic causes. Aggressive behavior improved in these patients as assessed by the Modified OAS (MOAS) as well as by the Quality of Life Scale (QOLS). ${ }^{60}$

In 2008, Hamani et al. reported on the case of a morbidly obese patient treated with bilateral DBS of the ventral hypothalamus. No weight change was observed in the first 6 months with high-frequency $(130-\mathrm{Hz})$ stimulation; however, the patient lost $12 \mathrm{~kg}$ following a 5-month period of low-frequency $(50-\mathrm{Hz})$ stimulation. The weight loss was seemingly due to a reduction in food craving and a decreased tendency to binge eat, with no intentional changes in his diet or changes in his exercise habits. Without stimulation, the binge-eating episodes returned, and the patient regained the weight he had lost. ${ }^{36}$

Following the reports by Hamani et al..$^{36}$ and others, ${ }^{73,113}$ an FDA-approved pilot study on DBS targeting the LHA for the treatment of refractory obesity was performed.112 
TABLE 2. Brief review of literature on hypothalamic DBS for behavioral disorders

\begin{tabular}{|c|c|c|c|c|c|}
\hline Authors \& Year & $\begin{array}{l}\text { No. of Pts } \\
\text { (sex) }\end{array}$ & Study Type & Target & Indication & Outcome \\
\hline Hamani et al., 2008 & $1(\mathrm{M})$ & Case report & $\begin{array}{l}\text { Ventral hypothal- } \\
\text { amus (bilat) }\end{array}$ & Refractory morbid obesity & $\begin{array}{l}\text { Reduced food cravings, }{ }^{*} \text { decreased tendency } \\
\text { to binge* }\end{array}$ \\
\hline $\begin{array}{l}\text { Hernando et al., } \\
2008\end{array}$ & $1(\mathrm{M})$ & Case report & PMH (bilat) & $\begin{array}{l}\text { Refractory aggressive behavior } \\
\text { associated } w / \text { mental } \\
\text { retardation }\end{array}$ & $\begin{array}{l}\text { Reduced aggressive behavior \& improved } \\
\text { social interactions, } † \text { simplification of familiar } \\
\text { management }\end{array}$ \\
\hline Kuhn et al., 2008 & $1(\mathrm{~F})$ & Case report & PMH (bilat) & $\begin{array}{l}\text { Refractory self-aggressive } \\
\text { behavior after brain injury }\end{array}$ & $\begin{array}{l}\text { Subjective experience of inner peace, disap- } \\
\text { pearance of self-aggressive behavior }\end{array}$ \\
\hline $\begin{array}{l}\text { Franzini et al., 2005, } \\
\text { 2007, } 2013\end{array}$ & $7(6 \mathrm{M}, 1 \mathrm{~F})$ & Case series & PMH (bilat) & $\begin{array}{c}\text { Refractory aggressiveness \& } \\
\text { severe mental retardation }\end{array}$ & $\begin{array}{l}\text { Reduced aggressiveness at } 1 \mathrm{yr} \text { in } 6 \text { of } 7 \mathrm{pts}, \ddagger \\
\text { improved family \& social interactions }\end{array}$ \\
\hline Torres et al., 2012 & $6(4 \mathrm{M}, 2 \mathrm{~F})$ & Case series & PMH (bilat) & $\begin{array}{l}\text { Refractory aggressive behavior } \\
\text { related to mental retardation }\end{array}$ & $\begin{array}{l}\text { Reduced aggressive behavior in } 5 \text { of } 6 \text { pts, } \dagger \\
\text { improved social interactions in } 3 \text { of } 6 \text { pts \& } \\
\text { sleep patterns in } 4 \text { of } 6 \text { pts }\end{array}$ \\
\hline Whiting et al., 2013 & $3(1 \mathrm{M}, 2 \mathrm{~F})$ & Pilot study & LHA (bilat) & Refractory morbid obesity & Decreased urge to eat, increased energy levels \\
\hline Micieli et al., 2016 & $4(3 \mathrm{M}, 1 \mathrm{~F})$ & Case series & PMH (bilat) & $\begin{array}{l}\text { Refractory aggressive behavior } \\
\text { related to mental retardation }\end{array}$ & $\begin{array}{l}\text { Reduced aggressive behavior \& improved } \\
\text { quality of life§ }\end{array}$ \\
\hline
\end{tabular}

Pts = patients.

* Only during the 5 months after the system was set to a lower frequency during which the patient kept the stimulation constantly turned on. These effects were not observed in high-frequency stimulation during the initial 6-month period.

$\uparrow$ Assessed by ICAP.

$\ddagger$ Assessed by OAS.

$\S$ Assessed by MOAS and QOLS.

At a mean duration of follow-up of 35 months, no serious long-term adverse effects (including unwanted psychological consequences) had been observed. After metabolically optimized LHA DBS settings, promising weight loss trends accompanied by a decreased urge to eat and increased subjective feelings of energy were reported. These effects proved reversible when the stimulator was turned off in a blinded fashion. ${ }^{66} \mathrm{~A}$ larger follow-up report focusing on efficacy and metabolic results is expected. ${ }^{24}$

Furthermore, sudden unexpected behavioral changes during implantation of DBS electrodes in the hypothalamus were reported in the literature (Table 3). Bejjani et al. reported on a case of a patient with advanced Parkinson's disease successfully treated by bilateral stimulation of the subthalamic nucleus who developed acute transient aggressive behavior during intraoperative electrical test stimulation. The authors suggest that the site where stimulation produced the rage episode was located on the exploratory medial track, at the lateral border of the PMH. ${ }^{11}$ This fortuitously evoked response paved the way for the rebirth of hypothalamic surgery for the treatment of aggressive behavior in mentally retarded patients. ${ }^{27}$

Other effects of hypothalamic DBS may also provide insights to tackle other psychiatric symptoms. The first reported series of ventroposterior hypothalamic (VPH) DBS for treatment of refractory chronic cluster headache $(\mathrm{CCH})$ featured a male patient with signs of mild hypersexual and hyperphagic behavior, which seemed to be resolved with stimulation; he lost $25 \mathrm{~kg}$ at 18 -month follow-up. ${ }^{28} \mathrm{In}$ other 2 reports of ipsilateral VPH DBS for $\mathrm{CCH}$, a total of 3 patients presented panic attacks during stimulation..$^{9,91}$ Schoenen et al. reported that one of their 6 patients needed to

TABLE 3. Unexpected behavioral changes evoked by DBS to the hypothalamus

\begin{tabular}{|c|c|c|c|c|c|}
\hline Authors \& Year & $\begin{array}{l}\text { No. of Pts } \\
\text { (sex) }\end{array}$ & Study Type & $\begin{array}{c}\text { DBS } \\
\text { Indication }\end{array}$ & Stimulation Site & Main Unexpected Effect \\
\hline Bejjani et al., 2002 & $1(\mathrm{M})$ & Case report & PD & Lat part of It PM hypothalamus & Induction of aggressive behavior \\
\hline Franzini et al., 2003 & $5(4 \mathrm{M}, 1 \mathrm{~F})$ & Case series & $\mathrm{CCH}$ & VPH (ipsilat) & Sex \& food intake normalization in 1 male pt $^{*}$ \\
\hline Schoenen et al., 2005 & $6(5 \mathrm{M}, 1 \mathrm{~F})$ & Case series & $\mathrm{CCH}$ & VPH (ipsilat) & Induction of panic attacks in $1 \mathrm{pt}$ \\
\hline Rasche et al., 2006 & $1(\mathrm{~F})$ & Case report & $\mathrm{CCH}$ & VPH (ipsilat) & Induction of panic attacks \\
\hline Bartsch et al., 2008 & $6(4 \mathrm{M}, 2 \mathrm{~F})$ & $\begin{array}{l}\text { Case series } \\
\quad \text { (multicenter) }\end{array}$ & $\mathrm{CCH}$ & VPH (ipsilat) & Induction of panic attacks in $2 \mathrm{pts}$ \\
\hline Hamani et al., 2008 & $1(\mathrm{M})$ & Case report & Obesity & Ventral hypothalamus (bilat) $†$ & Evocation of detailed autobiographical memories \\
\hline Wilent et al., 2010 & $1(\mathrm{~F})$ & Case report & Obesity & VMH (bilat) & Induction of panic attacks \\
\hline
\end{tabular}

$\mathrm{PD}=$ Parkinson's disease.

* Signs of mild hypersexual and hyperphagic behavior were observed in this patient prior to the operation; he had lost $25 \mathrm{~kg}$ by the 18 -month follow-up visit.

$\dagger$ Estimated to be in close association with the fornix. 
have the implantation procedure interrupted due to a panic attack associated with polypnea, tachycardia, and moderate hypertension. After the operation, the patient's vital signs returned to normal. ${ }^{91}$ In a multicenter case series reported by Bartsch et al., ${ }^{9} 2$ of 6 patients experienced panic as a side effect of DBS. Such episodes were not further described in this study. A similar case was reported by Rasche et al. ${ }^{75}$ a 39-year-old woman developed tachycardia, diplopia, and panic attacks during intraoperative test stimulation of the left ventroposterior for $\mathrm{CCH}$. Some authors consider these side effects typical of this procedure. ${ }^{9,75}$

In 2010, Wilent et al. reported panic attacks in response to stimulation of the VMH in a 50-year-old woman undergoing bilateral implantation of DBS leads into the lateral hypothalamus for the treatment of obesity. ${ }^{113}$ The patient had a dramatic increase in anxiety, blood pressure, and heart rate, accompanied by hyperventilation and nausea. While stimulation of this area in either hemisphere led to the aforementioned response, stimulation appeared to be more effective at the center of the $\mathrm{VMH}$.

A unique behavioral effect reported by Hamani and colleagues $^{36}$ in a patient treated with DBS for obesity was the elicitation of detailed autobiographical memories and déjà vu experiences during bilateral stimulation of contacts located in the ventral hypothalamus, which were estimated to be close to the fornix. An associative memory task administered in a double-blind stimulation on/off protocol indicated that stimulation increased recollection but not familiarity-based recognition, indicating a functional engagement of the hippocampus. Electroencephalographic source localization demonstrated that stimulation of this region in either hemisphere modulates activity in mesial temporal lobe structures related to memory. ${ }^{36}$

\section{Implications for the Future}

The hypothalamus has been used as a stereotactic target throughout the decades of the neurosurgical endeavor to ameliorate the mind and behavior in a host of otherwise hopeless psychiatric disorders. ${ }^{23,24,27,83,112}$ Neuroscience researchers have employed different techniques to reveal the minutiae of the functions of the hypothalamus, ranging from the tracing of fiber pathways to advanced molecular analysis. ${ }^{48,50,99}$ The hypothalamus mainly exerts an integrative role; that is, it receives a range of afferent inputs and effectuates autonomic, endocrine, and behavioral responses to achieve homeostasis through allostasis. ${ }^{87}$ Accordingly, the hypothalamus has been implicated in psychiatric diseases related to feeding, sexual behavior, aggression, and fear. Moreover, it can evoke self-related memories, usually described as pleasant experiences. ${ }^{36}$

Stereotactic approaches to specific nuclei or regions of the hypothalamus have provided a unique background for a better understanding of the neural basis of several behavioral disorders (obesity, aggressive behavior, panic disorder, addiction, and paraphilic disorders). ${ }^{11,23,29,33,36,113} \mathrm{~A}$ better understanding of the underlying circuitry of specific behavioral functions-i.e., feeding, drug consumption, aggression, sexuality, and fear-together with the implementation of neuromodulation paradigms (e.g., optogenetic stimulation, radiosurgery, focused ultrasound, intraoperative electrophysiological mapping) and the prediction of the network-level response to different focal stimulations of hypothalamic nuclei or white matter fibers (i.e., with simulation studies) may lead to the development of novel and optimized stereotactic targets and clinical trials of neurosurgery for psychiatric disorders. ${ }^{4,20,55,63}$

\section{Summary and Conclusions}

Interest in the hypothalamus as a potential target for psychosurgery dates back to the beginning of the 20th century ${ }^{18,19,39}$ This interest was channeled into practical action following the adaptation of the stereotactic apparatus to human patients, allowing neurosurgeons to aim at the hypothalamus with unprecedented precision. ${ }^{96}$ Initially, the choice of specific targets was largely based on inferences from animal studies and on a few cases of relatively discrete war injuries of the basal forebrain. ${ }^{41,83}$ In the $1960 \mathrm{~s}$ and 1970s, hypothalamotomies were performed for intractable aggressiveness associated with mental retardation, morbid obesity, sexual deviations, and alcohol and drug dependence. ${ }^{33,64,73,83}$ Despite a lack of consistent scientific support and the fierce opposition put up by both medical professionals and the mass media, hypothalamotomy and, for that matter, psychosurgery as a whole, became increasingly popular from 1935 to the late 1950s. During this period, surgery for the treatment of mental illness was performed in several countries, including Brazil; although its frequency decreased dramatically in the mid-1950s after reserpine and chlorpromazine were introduced into clinical practice, surgical treatment continued to be performed in a few medical centers. ${ }^{10,16,56,100}$

Notwithstanding the lack of consensus in critical areas, the experience of the past 80 years should provide a valuable contribution to the understanding of the neurology of mental illnesses and the trails to be followed in the pursuit of novel therapeutic strategies. The slow resurgence of psychosurgery in the past decades has been propelled by its increasing acceptance by lay people as well as by the recognition of the failure of pharmacological treatments in at least $20 \%$ of patients with the severest forms of mental disorders. It may seem ironic that we stand today in a situation that in some ways resembles the one we faced in the initial decades of the twentieth century, when legions of human beings were hopelessly disabled by mental illness. ${ }^{107}$ The time could hardly be more auspicious for the development of novel ways of treating them and alleviating their suffering. The rebirth of psychosurgery is a promising avenue in this direction. ${ }^{40}$

\section{References}

1. Alt KW, Jeunesse C, Buitrago-Téllez CH, Wächter R, Boës E, Pichler SL: Evidence for stone age cranial surgery. Nature 387:360, 1997

2. Alterman RL, Sterio D, Beric A, Kelly PJ: Microelectrode recording during posteroventral pallidotomy: impact on target selection and complications. Neurosurgery 44:315323,1999

3. Anand BK, Brobeck JR: Hypothalamic control of food intake in rats and cats. Yale J Biol Med 24:123-140, 1951

4. Anderson DJ: Optogenetics, sex, and violence in the brain: implications for psychiatry. Biol Psychiatry 71:1081-1089, 2012

5. Angelergues R, De Ajuriaguerra J, Hecaen H: [Paralysis of 
the upward movement of the eyes of vascular origin; anatomoclinical study.] Rev Neurol (Paris) 96:301-319, 1957 (Fr)

6. Arjona VE: Sterotactic hypothalamotomy in erethic children. Acta Neurochir Suppl 21:185-191, 1974

7. Balasubramaniam V, Kanaka TS: Amygdalotomy and hypothalamotomy - a comparative study. Confin Neurol 37:195-201, 1975

8. Balthazart J, de Meaultsart CC, Ball GF, Cornil CA: Distinct neuroendocrine mechanisms control neural activity underlying sex differences in sexual motivation and performance. Eur J Neurosci 37:735-742, 2013

9. Bartsch T, Pinsker MO, Rasche D, Kinfe T, Hertel F, Diener HC, et al: Hypothalamic deep brain stimulation for cluster headache: experience from a new multicase series. Cephalalgia 28:285-295, 2008

10. Baumeister AA: The chlorpromazine enigma. J Hist Neurosci 22:14-29, 2013

11. Bejjani BP, Houeto JL, Hariz M, Yelnik J, Mesnage V, Bonnet AM, et al: Aggressive behavior induced by intraoperative stimulation in the triangle of Sano. Neurology 59: 1425-1427, 2002

12. Broggi G, Franzini A: Treatment of aggressive behavior in, Lozano AM, Gildenberg P, Tasker R (eds): Textbook of Stereotactic and Functional Neurosurgery, ed 2. Berlin: Springer, 2009, pp 2971-2977

13. Boulant JA: Role of the preoptic-anterior hypothalamus in thermoregulation and fever. Clin Infect Dis 31 (Suppl 5):S157-S161, 2000

14. Charlier TD, Ball GF, Balthazart J: Rapid action on neuroplasticity precedes behavioral activation by testosterone. Horm Behav 54:488-495, 2008

15. Coenen VA, Schlaepfer TE, Maedler B, Panksepp J: Crossspecies affective functions of the medial forebrain bundleimplications for the treatment of affective pain and depression in humans. Neurosci Biobehav Rev 35:1971-1981, 2011

16. Collins BM, Stam HJ: A transnational perspective on psychosurgery: beyond Portugal and the United States. J Hist Neurosci 23:335-354, 2014

17. Contreras M, Riveros ME, Quispe M, Sánchez C, Perdomo $\mathrm{G}$, Torrealba F, et al: The histaminergic tuberomamillary nucleus is involved in appetite for sex, water and amphetamine. PLoS One 11:e0148484, 2016

18. Cushing H: Neurohypophyseal mechanisms from a clinical standpoint. Part I. Lancet 216:119-127, 1930

19. Cushing H: Neurohypophyseal mechanisms from a clinical standpoint. Part II. Lancet 216:175-184, 1930

20. De Salles A, Gorgulho AA: Radiosurgery for psychiatric disorders, in Sun B, De Salles A (eds): Neurosurgical Treatments for Psychiatric Disorders. New York: Springer, 2015, pp 217-225

21. Delgado JM, Anand BK: Increase of food intake induced by electrical stimulation of the lateral hypothalamus. Am J Physiol 172:162-168, 1953

22. Dieckmann G, Schneider H: Influence of stereotactic hypothalamotomy on alcohol and drug addiction. Appl Neurophysiol 41:93-98, 1978

23. Dieckmann G, Schneider-Jonietz B, Schneider H: Psychiatric and neuropsychological findings after stereotactic hypothalamotomy, in cases of extreme sexual aggressivity. Acta Neurochir Suppl (Wien) 44:163-166, 1988

24. Dupré DA, Tomycz N, Oh MY, Whiting D: Deep brain stimulation for obesity: past, present, and future targets. Neurosurg Focus 38(6):E7, 2015

25. Ebner K, Muigg P, Singewald N: Inhibitory function of the dorsomedial hypothalamic nucleus on the hypothalamicpituitary-adrenal axis response to an emotional stressor but not immune challenge. J Neuroendocrinol 25:48-55, 2013
26. Foerster O, Gagel O: [A case of colloid cyst of the third ventricle. A input to the question of the relationship between psychiatric disorders and the brainstem.] $\mathbf{Z}$ Gesamte Neurol Psychiatr 149:312-344, 1933 (Ger)

27. Franzini A, Broggi G, Cordella R, Dones I, Messina G: Deep-brain stimulation for aggressive and disruptive behavior. World Neurosurg 80:S29.e11-S29.e14, 2013

28. Franzini A, Ferroli P, Leone M, Broggi G: Stimulation of the posterior hypothalamus for treatment of chronic intractable cluster headaches: first reported series. Neurosurgery 52:1095-1101, 2003

29. Franzini A, Marras C, Ferroli P, Bugiani O, Broggi G: Stimulation of the posterior hypothalamus for medically intractable impulsive and violent behavior. Stereotact Funct Neurosurg 83:63-66, 2005

30. Franzini A, Marras C, Tringali G, Leone M, Ferroli P, Bussone $\mathrm{G}$, et al: Chronic high frequency stimulation of the posteromedial hypothalamus in facial pain syndromes and behaviour disorders. Acta Neurochir Suppl 97:399-406, 2007

31. Franzini A, Messina G, Cordella R, Marras C, Broggi G: Deep brain stimulation of the posteromedial hypothalamus: indications, long-term results, and neurophysiological considerations. Neurosurg Focus 29(2):E13, 2010

32. Fulgraff G, Barbey I: [Stereotactic neurosurgery for anomalous sexual behavior.] Abschlussbericht der Kommission beim Bundesgesundheitsamt. Berlin: Reimer, 1978 (Ger)

33. Fuss J, Auer MK, Biedermann SV, Briken P, Hacke W: Deep brain stimulation to reduce sexual drive. J Psychiatry Neurosci 40:429-431, 2015

34. Gooley JJ, Schomer A, Saper CB: The dorsomedial hypothalamic nucleus is critical for the expression of foodentrainable circadian rhythms. Nat Neurosci 9:398-407, 2006

35. Halász B, Pupp L, Uhlarik S: Hypophysiotrophic area in the hypothalamus. J Endocrinol 25:147-154, 1962

36. Hamani C, McAndrews MP, Cohn M, Oh M, Zumsteg $\mathrm{D}$, Shapiro CM, et al: Memory enhancement induced by hypothalamic/fornix deep brain stimulation. Ann Neurol 63:119-123, 2008

37. Herman JP, McKlveen JM, Ghosal S, Kopp B, Wulsin A, Makinson R, et al: Regulation of the hypothalamicpituitary-adrenocortical stress response. Compr Physiol 6:603-621, 2016

38. Hernando V, Pastor J, Pedrosa M, Peña E, Sola RG: Lowfrequency bilateral hypothalamic stimulation for treatment of drug-resistant aggressiveness in a young man with mental retardation. Stereotact Funct Neurosurg 86:219-223, 2008

39. Ingram WR: Nuclear organization and chief connections of the primate hypothalamus. Res Publ Assoc Res Nerv Ment Dis 20:195-244, 1940

40. Jarema M: Biological treatment in psychiatry: beyond pharmacology. Neuro Endocrinol Lett 29 (Suppl 1):7-68, 2008

41. Kleist K: [War injuries of the brain and their implications for neuroanatomy and neuropathology.] Handbuch der ärztlichen Erfahrungen im Weltkriege 1914/1918. Leipzig: Barth, 1934 (Ger)

42. Klingler J, Gloor P: The connections of the amygdala and of the anterior temporal cortex in the human brain. J Comp Neurol 115:333-369, 1960

43. Kotowicz Z: Gottlieb Burckhardt and Egas Moniz-two beginnings of psychosurgery. Gesnerus 62:77-101, 2005

44. Kuhn J, Lenartz D, Mai JK, Huff W, Klosterkoetter J, Sturm V: Disappearance of self-aggressive behavior in a brain-injured patient after deep brain stimulation of the hypothalamus: technical case report. Neurosurgery 62:E1182, 2008

45. Laćan G, De Salles AA, Gorgulho AA, Krahl SE, Frighetto 
L, Behnke EJ, et al: Modulation of food intake following deep brain stimulation of the ventromedial hypothalamus in the vervet monkey. J Neurosurg 108:336-342, 2008

46. Lang J: Surgical anatomy of the hypothalamus. Acta Neurochir (Wien) 75:5-22, 1985

47. Le Gros Clark WE: The topography and homologies of the hypothalamic nuclei in man. J Anat 70:203-214, 3, 1936

48. Lein ES, Hawrylycz MJ, Ao N, Ayres M, Bensinger A, Bernard A, et al: Genome-wide atlas of gene expression in the adult mouse brain. Nature 445:168-176, 2007

49. Lemaire JJ: Related circuitry and synaptic connectivity in psychiatric disorders, in Sun B, De Salles A (eds): Neurosurgical Treatments for Psychiatric Disorders. New York: Springer, 2015, pp 1-20

50. Lemaire JJ, Frew AJ, McArthur D, Gorgulho AA, Alger JR, Salomon N, et al: White matter connectivity of human hypothalamus. Brain Res 1371:43-64, 2011

51. Lemaire JJ, Nezzar H, Sakka L, Boirie Y, Fontaine D, Coste A, et al: Maps of the adult human hypothalamus. Surg Neurol Int 4 (Suppl 3):S156-S163, 2013

52. Lin D, Boyle MP, Dollar P, Lee H, Lein ES, Perona P, et al: Functional identification of an aggression locus in the mouse hypothalamus. Nature 470:221-226, 2011

53. Lu L, Wang X, Kosten TR: Stereotactic neurosurgical treatment of drug addiction. Am J Drug Alcohol Abuse 35:391-393, 2009

54. Manjila S, Rengachary S, Xavier AR, Parker B, Guthikonda M: Modern psychosurgery before Egas Moniz: a tribute to Gottlieb Burckhardt. Neurosurg Focus 25(1):E9, 2008

55. Martin E, Jeanmonod D, Morel A, Zadicario E, Werner B: High-intensity focused ultrasound for noninvasive functional neurosurgery. Ann Neurol 66:858-861, 2009

56. Masiero AL: [Lobotomy and leucotomy in Brazilian mental hospitals.] Hist Cienc Saude Manguinhos 10:549-572, 2003 (Portuguese)

57. Melega WP, Lacan G, Gorgulho AA, Behnke EJ, De Salles AA: Hypothalamic deep brain stimulation reduces weight gain in an obesity-animal model. PLoS One 7:e30672, 2012

58. Meyers R: Evidence of a locus of the neural mechanisms for libido and penile potency in the septo-fornico-hypothalamic region of the human brain. Trans Am Neurol Assoc 86:81-85, 1961

59. Meyers R: Three cases of myoclonus alleviated by bilateral ansotomy, with a note on postoperative alibido and impotence. J Neurosurg 19:71-81, 1962

60. Micieli R, Rios AL, Aguilar RP, Posada LF, Hutchison WD: Single-unit analysis of the human posterior hypothalamus and red nucleus during deep brain stimulation for aggressivity. J Neurosurg 126:1158-1164, 2017

61. Minor RK, Chang JW, de Cabo R: Hungry for life: How the arcuate nucleus and neuropeptide $\mathrm{Y}$ may play a critical role in mediating the benefits of calorie restriction. Mol Cell Endocrinol 299:79-88, 2009

62. Moniz E: Prefrontal leucotomy in the treatment of mental disorders. Am J Psychiatry 93:1379-1385, 1937

63. Mulgaonkar AP, Singh RS, Babakhanian M, Culjat MO, Grundfest WS, Gorgulho A, et al: A prototype stimulator system for noninvasive low intensity focused ultrasound delivery. Stud Health Technol Inform 173:297-303, 2012

64. Müller D, Roeder F, Orthner H: Further results of stereotaxis in the human hypothalamus in sexual deviations. First use of this operation in addiction to drugs. Neurochirurgia (Stuttg) 16:113-126, 1973

65. Musiek ES, Holtzman DM: Mechanisms linking circadian clocks, sleep, and neurodegeneration. Science 354:10041008, 2016

66. Nangunoori RK, Tomycz ND, Oh MY, Whiting DM: Deep brain stimulation for obesity: from a theoretical framework to practical application. Neural Plast 2016:7971460, 2016
67. Nauta WJ: Hypothalamic regulation of sleep in rats; an experimental study. J Neurophysiol 9:285-316, 1946

68. Nauta WJH, Domesick VB: Ramifications of the limbic system, in Matthysse S (ed): Psychiatry and the Biology of the Human Brain: A Symposium Dedicated to Seymour S. Kety. New York: Elsevier, 1981, pp 165-188

69. Nauta WJ, Haymaker W: Hypothalamic nuclei and fiber connections, in Haymaker W, Anderson E, Nauta WJ (eds): The Hypothalamus. Springfield, IL: Charles C Thomas, 1969, pp 136-200

70. Oomura Y, Ono T, Ooyama H, Wayner MJ: Glucose and osmosensitive neurones of the rat hypothalamus. Nature 222:282-284, 1969

71. Parmentier R, Kolbaev S, Klyuch BP, Vandael D, Lin JS, Selbach O, et al: Excitation of histaminergic tuberomamillary neurons by thyrotropin-releasing hormone. J Neurosci 29:4471-4483, 2009

72. Quaade F: Stereotaxy for obesity. Lancet 1:267, 1974 (Letter)

73. Quaade F, Vaernet K, Larsson S: Stereotaxic stimulation and electrocoagulation of the lateral hypothalamus in obese humans. Acta Neurochir (Wien) 30:111-117, 1974

74. Ramamurthi B: Stereotactic operation in behaviour disorders. Amygdalotomy and hypothalamotomy. Acta Neurochir Suppl (Wien) 44:152-157, 1988

75. Rasche D, Foethke D, Gliemroth J, Tronnier VM: [Deep brain stimulation in the posterior hypothalamus for chronic cluster headache. Case report and review of the literature.] Schmerz 20:439-444, 2006 (Ger)

76. Rieber I, Sigusch V: Psychosurgery on sex offenders and sexual "deviants" in West Germany. Arch Sex Behav 8:523-527, 1979

77. Roeder FD: Stereotaxic lesion of the tubular cinereum in sexual deviation. Confin Neurol 27:162-163, 1966

78. Roeder F, Müller D: [On stereotaxic cure of pedophilic homosexuality.] Dtsch Med Wochenschr 94:409-415, 1969 (Ger)

79. Roeder F, Müller D, Orthner H: [Further experiences with the stereotactic management of sexual perversion.] J Neural Transm Suppl 10:317-324, 1971 (Ger)

80. Roeder F, Orthner H, Müller D: The stereotaxic treatment of pedophilic homosexuality and other sexual deviations, in Hitchcock E, Laitinen L, Vaernet KC (eds): Psychosurgery. Springfield: Charles C Thomas, 1972, pp 87-111

81. Sagar SM, Martin JB: Hypothalamohypophysiotropic peptide systems, in Bloom FE (ed): Handbook of Physiology. Section 1: The Nervous System, Volume IV: Intrinsic Regulatory Systems of the Brain. New York: Oxford University Press, 1986, pp 413-462

82. Salcman M: The cure of folly or The operation for the stone by Hieronymus Bosch (C. 1450-1516). Neurosurgery 59:935-937, 2006

83. Sano K: Sedative neurosurgery with special reference to posteromedial hypothalamotomy. Neurol Med Chir (Tokyo) 4:112-142, 1962

84. Sano K, Mayanagi Y: Posteromedial hypothalamotomy in the treatment of violent, aggressive behaviour. Acta Neurochir Suppl (Wien) 44:145-151, 1988

85. Sano K, Mayanagi Y, Sekino H, Ogashiwa M, Ishijima B: Results of stimulation and destruction of the posterior hypothalamus in man. J Neurosurg 33:689-707, 1970

86. Sano K, Yoshioka M, Ogashiwa M, Ishijima B, Ohye $\mathrm{C}$ : Postero-medial hypothalamotomy in the treatment of aggressive behaviors. Confin Neurol 27:164-167, 1966

87. Saper CB: Hypothalamus, in Mai JK, Paxinos G (eds): The Human Nervous System, ed 3. London: Academic Press, 2011, pp 548-583

88. Saper CB, Lowell BB: The hypothalamus. Curr Biol 24:R1111-R1116, 2014 
89. Sapru HN: Role of the hypothalamic arcuate nucleus in cardiovascular regulation. Auton Neurosci 175:38-50, 2013

90. Schmidt G, Schorsch E: Psychosurgery of sexually deviant patients: review and analysis of new empirical findings. Arch Sex Behav 10:301-323, 1981

91. Schoenen J, Di Clemente L, Vandenheede M, Fumal A, De Pasqua V, Mouchamps M, et al: Hypothalamic stimulation in chronic cluster headache: a pilot study of efficacy and mode of action. Brain 128:940-947, 2005

92. Schvarcz JR, Driollet R, Rios E, Betti O: Stereotactic hypothalamotomy for behaviour disorders. J Neurol Neurosurg Psychiatry 35:356-359, 1972

93. Schwartz MW, Seeley RJ, Campfield LA, Burn P, Baskin DG: Identification of targets of leptin action in rat hypothalamus. J Clin Invest 98:1101-1106, 1996

94. Shekhar A, DiMicco JA: Defense reaction elicited by injection of GABA antagonists and synthesis inhibitors into the posterior hypothalamus in rats. Neuropharmacology 26:407-417, 1987

95. Soriano-Mas C, Redolar-Ripoll D, Aldavert-Vera L, Morgado-Bernal I, Segura-Torres P: Post-training intracranial self-stimulation facilitates a hippocampus-dependent task. Behav Brain Res 160:141-147, 2005

96. Spiegel EA, Wycis HT, Marks M, Lee AJ: Stereotaxic apparatus for operations on the human brain. Science 106:349-350, 1947

97. Sternson SM: Hypothalamic survival circuits: blueprints for purposive behaviors. Neuron 77:810-824, 2013

98. Stuber GD, Wise RA: Lateral hypothalamic circuits for feeding and reward. Nat Neurosci 19:198-205, 2016

99. Swanson LW, Hartman BK: The central adrenergic system. An immunofluorescence study of the location of cell bodies and their efferent connections in the rat utilizing dopaminebeta-hydroxylase as a marker. J Comp Neurol 163:467505,1975

100. Swayze VW II: Frontal leukotomy and related psychosurgical procedures in the era before antipsychotics (1935-1954): a historical overview. Am J Psychiatry 152:505-515, 1995

101. Tokunaga K, Fukushima M, Kemnitz JW, Bray GA: Comparison of ventromedial and paraventricular lesions in rats that become obese. Am J Physiol 251:R1221-R1227, 1986

102. Torrealba F, Riveros ME, Contreras M, Valdes JL: Histamine and motivation. Front Syst Neurosci 6:51, 2012

103. Torres CV, Sola RG, Pastor J, Pedrosa M, Navas M, García-Navarrete E, et al: Long-term results of posteromedial hypothalamic deep brain stimulation for patients with resistant aggressiveness. J Neurosurg 119:277-287, 2013

104. Torres N, Chabardes S, Piallat B, Devergnas A, Benabid AL: Body fat and body weight reduction following hypothalamic deep brain stimulation in monkeys: an intraventricular approach. Int J Obes 36: 1537-1544, 2012

105. Ulrich-Lai YM, Herman JP: Neural regulation of endocrine and autonomic stress responses. Nat Rev Neurosci 10:397409, 2009

106. U.S. Department of Health, Education, and Welfare: Protection of human subjects. Use of psychosurgery in prac- tice and research: report and recommendations of National Commission for the Protection of Human Subjects. Fed Regist 42:26318-26332, 1977

107. Valenstein ES: Great and Desperate Cures. New York: Basic Books, 1986

108. van Praag HM: Two-tier diagnosing in psychiatry. Psychiatry Res 34:1-11, 1990

109. Vann SD: Re-evaluating the role of the mammillary bodies in memory. Neuropsychologia 48:2316-2327, 2010

110. von Economo C: Sleep as a problem of localization. J Nerv Ment Dis 71:249-259, 1930

111. Wheatley MD: The hypothalamus and affective behavior in cats: a study of the effects of experimental lesions, with anatomic correlations. Arch Neurol Psychiatry 52:296316, 1944

112. Whiting DM, Tomycz ND, Bailes J, de Jonge L, Lecoultre V, Wilent B, et al: Lateral hypothalamic area deep brain stimulation for refractory obesity: a pilot study with preliminary data on safety, body weight, and energy metabolism. J Neurosurg 119:56-63, 2013

113. Wilent WB, Oh MY, Buetefisch CM, Bailes JE, Cantella $\mathrm{D}$, Angle $\mathrm{C}$, et al: Induction of panic attack by stimulation of the ventromedial hypothalamus. J Neurosurg 112:12951298,2010

114. Yang CF, Chiang MC, Gray DC, Prabhakaran M, Alvarado M, Juntti SA, et al: Sexually dimorphic neurons in the ventromedial hypothalamus govern mating in both sexes and aggression in males. Cell 153:896-909, 2013

115. Zhang W, Cline MA, Gilbert ER: Hypothalamus-adipose tissue crosstalk: neuropeptide $\mathrm{Y}$ and the regulation of energy metabolism. Nutr Metab (Lond) 11:27, 2014

\section{Disclosures}

The authors report no conflict of interest concerning the materials or methods used in this study or the findings specified in this paper.

\section{Author Contributions}

Conception and design: Barbosa, de Oliveira-Souza, Monte Santo, De Salles. Acquisition of data: Barbosa, de Oliveira-Souza, de Oliveira Faria, Gorgulho. Analysis and interpretation of data: Barbosa, de Oliveira-Souza, de Oliveira Faria, De Salles. Drafting the article: Barbosa, de Oliveira-Souza, Monte Santo, de Oliveira Faria. Critically revising the article: Barbosa, de Oliveira-Souza, Monte Santo, Gorgulho, De Salles. Reviewed submitted version of manuscript: all authors. Approved the final version of the manuscript on behalf of all authors: Barbosa. Study supervision: de Oliveira-Souza, Gorgulho, De Salles.

\section{Correspondence}

Daniel Alves Neiva Barbosa, D’Or Institute for Research \& Education (IDOR), Rua Diniz Cordeiro, 30, 2nd Fl., Botafogo, Rio de Janeiro-RJ 22281-100, Brazil. email: danielbarbosa9@hotmail. com. 